\title{
Primary impact of Gli1 on radioresistance in esophageal cancer
}

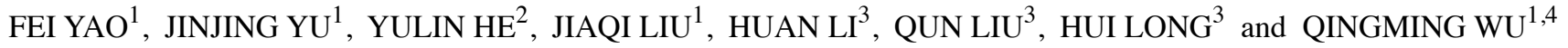 \\ ${ }^{1}$ Department of Public Health and Preventive Medicine, School of Medicine, Wuhan University of Science and Technology, \\ Wuhan, Hubei 430065; ${ }^{2}$ Institute of Biomedical Research, Taihe Hospital, Hubei University of Medicine, Shiyan, \\ Hubei 442000; ${ }^{3}$ Department of Gastroenterology, Tianyou Hospital Affiliated to Wuhan University of Science and Technology; \\ ${ }^{4}$ Hubei Province Key Laboratory of Occupational Hazard Identification and Control, \\ Wuhan University of Science and Technology, Wuhan, Hubei 430065, P.R. China
}

Received November 12, 2018; Accepted July 26, 2019

DOI: $10.3892 / \mathrm{ol} .2019 .10837$

\begin{abstract}
Radioresistance is the primary cause for the low efficacy of radiotherapy in the treatment of esophageal cancer (EC). Increasing evidence has demonstrated that the Sonic Hedgehog (Shh) signaling pathway may be involved in the pathology of various tumors, including EC. The present study aimed to examine the association between radioresistance in EC and the Sonic Hedgehog pathway, and to determine whether a downstream transcription factor of the Shh pathway, glioma-associated oncogene family zinc finger 1 (Gli1), serves a primary role in radioresistance. The radiation-resistant cell line Eca109R was established by repeated low dose (cumulative dose $60 \mathrm{~Gy}$ ) irradiation of the human EC cell line Eca109. The level of cell radiosensitivity was determined by colony formation assay, and the localization of Gli1 was detected using immunofluorescence. Western blotting was used to determine the protein expression levels of Gli1, Shh, patched 1 (Ptch) and smoothened frizzled class receptor (Smo) in the two cell lines. Significantly higher levels of Glil were identified in the Eca109R cell line compared with those inEca109 cells $(\mathrm{P}<0.05)$. Additionally, western blotting analysis demonstrated an increased expression level of the Gli1, Shh, Ptch and Smo proteins in Eca109R, compared with Eca109 cells $(\mathrm{P}<0.05)$. Overexpression of Glil in the parental cell line led to decreased levels of radiosensitivity and radiosensitivity of the radioresistant cell line was restored through knockdown of Gli1. The present study demonstrated that Glil may be associated with the development of radioresistance in EC.
\end{abstract}

Correspondence to: Dr Qingming Wu, Department of Public Health and Preventive Medicine, School of Medicine, Wuhan University of Science and Technology, 2 Huangjiahu West Road, Hongshan, Wuhan, Hubei 430065, P.R. China

E-mail:wuhe9224@sina.com

Key words: esophageal cancer, radioresistance, Sonic Hedgehog signaling pathway, glioma-associated oncogene family zinc finger 1

\section{Introduction}

One of the most common types of cancer affecting the digestive system is esophageal cancer (EC). EC is a malignant cancer listed globally as the sixth highest in mortality rate and seventh highest in frequency of occurrence (1-3). Esophageal squamous cell cancer (ESCC) is the predominant type of EC, as nine out of 10 people living with $\mathrm{EC}$ in China are diagnosed with this subtype (4). The other subtype is esophageal adenocarcinoma (EA) $(5,6)$. The majority of patients are diagnosed in an advanced stage of the disease due to indiscernible early symptoms and a lack of efficacious screening methods $(7,8)$. Extensive research focused on the elucidation of the pathophysiological mechanisms of EC has been performed $(9,10)$; however, the 5-year survival rate of patients with EC is only 15 to $25 \%$ and the recurrence rate is $\sim 38.14 \%$, which results in the continued severity of this disease $(11,12)$. Various treatment options are available for EC, including chemotherapy, radiotherapy, surgery and comprehensive therapy (13). The optimum treatment plan for patients with advanced EC is a combination of surgery and radiotherapy $(14,15)$. However, reduced treatment efficacy is a consequence of the development of radioresistant tumor cells following radiotherapy, which is the major clinical obstacle in the treatment of EC (16). Thus, the establishment of efficacious means of improving tumor cell radiosensitivity is crucial to successful EC therapy.

At present, an increasing number of studies have reported the abnormal activation of the Sonic Hedgehog (Shh) signaling pathway in several types of human cancer, including hepatic, breast, bladder and pancreatic cancers (17-20). The majority of these studies focused on the association between tumor cell radioresistance and the Shh signaling pathway; however, there are a few studies on radioresistance in EC and Shh signaling pathway. A previous study established the inhibitory effect of $\mathrm{P} 162$, which is a new peptide with anti-cancer mechanism, on glioma-associated oncogene family zinc finger 1 (Gli1), which resulted in noticeable improvements in the level of radiosensitivity in EC cells (21). The present study aimed to establish the association between Shh signaling pathway activation and EC cell radiosensitivity.

The current study examined the contribution of Gli1, a factor in the Shh signaling pathway, to the radiosensitivity 
of EC cells. The results of the present study may form the foundation for enhancing radiotherapy efficacy as part of the treatment regimen for future patients with EC.

\section{Materials and methods}

Cell culture. The Eca109 cell line was supplied by Taihe Hospital, an affiliate of Hubei Medical College (Shiyan, China). Cells were maintained in liquid nitrogen and cultured in Dulbecco's modified Eagle's medium (Gibco; Thermo Fisher Scientific, Inc.) supplemented with fetal bovine serum $(10 \%)$ and penicillin $(100 \mu \mathrm{g} / \mathrm{ml})$ in a humidified atmosphere at $37^{\circ} \mathrm{C}$ and $5 \% \mathrm{CO}_{2}$.

Eca109R cell line establishment. X-ray irradiation of the Eca109 parental cell line was performed during the logarithmic growth phase at an absorbance dose rate of $2 \mathrm{~Gy} / \mathrm{min}$ using the Varian 2300 linear accelerator (6MV). On reaching $90 \%$ confluence, the cells were digested with trypsin in $0.25 \%$ EDTA, reinoculated and treated with repeated irradiation (2 Gy) during the logarithmic growth phase. A cumulative irradiation dose of $60 \mathrm{~Gy}$ was achieved by repeating the process 30 times. Subculture of the cells was performed to establish stable morphology, resulting in the formation of the radiation-resistant Eca109R cell line. Following continuous culturing over two weeks, the cells were separated into two batches, one of which was stored in liquid nitrogen, whereas the other continued to be subcultured. The Eca109R cell line was still resistant to radiation through 50 generations of subculturing without irradiation.

Clone formation assay. A single cell suspension of Eca109 and Eca109R cells was prepared following trypsinization of each cell line in the logarithmic growth phase. Cells were seeded at a range of concentrations $(400,400,800,1,000$ and 1,200 cells/well) in six-well plates and irradiated with 0 , 2, 4, 6 and $8 \mathrm{~Gy}$, with an average dose rate of $200 \mathrm{cGy} / \mathrm{min}$. Following a two-week incubation period, the cells were fixed with pure methanol at room temperature for $15 \mathrm{~min}$, stained with crystal violet at room temperature for $30 \mathrm{~min}$ and examined under a light microscope. Colony numbers were counted; a cell number $\geq 50$ cells was used as a clone. The cell survival curve was established using a single hit multi-target model, which allowed the calculation of various parameters, including the average lethal dose (D0), the quasi-threshold dose (Dq), the value of curve extension to the Y-axis intercept $(\mathrm{N})$ and the cell survival fraction following irradiation with $2 \mathrm{~Gy}\left(\mathrm{SF}_{2}\right)$. These experiments were performed three times.

Immunofluorescence assay. Immunofluorescence was used to determine Gli1 protein expression. Following fixation of Eca109 and Eca109R cells onto microscope slides with pure methanol at room temperature for $15 \mathrm{~min}$, the cells were blocked for $10 \mathrm{~min}$ with $10 \%$ goat serum (ZSBG-Bio), followed by incubation with the primary antibody against Gli1 (1:150; cat. no. NBP2-45872; Novus Biologicals) for $1 \mathrm{~h}$ at $37^{\circ} \mathrm{C}$. The cells were then washed with PBS three times prior to incubation with goat anti-mouse $\operatorname{IgG} H \& \mathrm{~L}$ secondary antibody (1:500; cat. no. ab150113; Abcam) for 1.5 hat $37^{\circ} \mathrm{C}$ in the dark. Following counterstaining with DAPI at room temperature for
$10 \mathrm{~min}$, the cells were examined using fluorescence microscopy (eight fields examined) and the experiment was repeated three times. Image J 15.0 software (National Institutes of Health) was used to measure the expression level of Gli1.

Western blotting analysis. Eca109 and Eca109R cells were lysed using RIPA lysis buffer (Beyotime Institute of Biotechnology) for $30 \mathrm{~min}$ at room temperature. Cells were centrifuged at $12,000 \mathrm{x}$ g for $15 \mathrm{~min}$ at $4^{\circ} \mathrm{C}$ and the supernatant was collected. The BCA Protein Quantitative Assay kit (Servicebio) was used to determine the protein concentration. The samples were denatured by boiling prior to separation (35 $\mu \mathrm{g}$ per lane) using 10\% SDS-PAGE followed by transfer to nitrocellulose membranes. Skimmed milk (5\%) was used as a blocking agent for $1.5 \mathrm{~h}$ at room temperature. Next, the membranes were incubated on a shaker with the primary antibodies against Gli1 $(1: 2,000$; cat. no. NBP2-45872; Novus Biologicals), Shh (1:5,000; cat. no. ab53281; Abcam), Smo (1:200; cat. no. GTX60154; GeneTex, Inc.), Ptch (1:500; cat. no. GTX83771; GeneTex, Inc.) and $\beta$-actin (1:5,000; cat. no. GTX629630; GeneTex, Inc.), overnight at $4^{\circ} \mathrm{C}$, washed with Tris-buffered saline with $0.05 \%$ Tween-20, and incubated with secondary antibodies (1:4,000; cat. nos. 1031-05 and 4050-05; Southern Biotech) for $1 \mathrm{~h}$ at $37^{\circ} \mathrm{C}$. Bands were detected using enhanced chemiluminescence substrate (Bio-Rad Laboratories, Inc.), and grayscale images were analyzed with ImageJ 15.0 software (National Institutes of Health). This procedure was performed three times.

Cell transfection. For Gli1 overexpression, the full-length Gli1 sequence was synthesized by cloning the Gli1 gene into the GV146 vector (Shanghai GeneChem Co., Ltd.) via XhoI and EcoRI sites, and was referred to as pGli1-IRES-EGFP. Empty GV146 vector acted as a negative control (NC) of pGli1-IRES-EGFP and was referred to as pIRES-EGFP. For knockdown of Gli1, short hairpin RNA (shRNA) directed against Gli1 was ligated into the GV102 vector (Shanghai GeneChem Co., Ltd.) and was referred to as sh-Gli1; a non-targeting sequence was ligated into the GV102 vector as the NC of sh-Gli1, and was referred to as sh-NC. The target sequence was 5'-CCTCTGTCTACT CACCACA-3' and the NC sequence was 5'-TTCTCCGAACGT GTCACGT-3'. Eca109 and Eca109R cells were seeded in 6-well plates at a density of $6 \times 10^{5}$ cells/well one day before transfection. Briefly, $5 \mu 1$ Lipofectamine ${ }^{\circledR} 3000$ reagent (Invitrogen; Thermo Fisher Scientific, Inc.) and $2.5 \mu \mathrm{g}$ plasmid were diluted into $125 \mu \mathrm{l}$ Opti-MEM (Gibco; Thermo Fisher Scientific, Inc.) and mixed for 5 min at room temperature. Cells were then incubated with this solution, and complete medium was added to the final volume of $2 \mathrm{ml}$. Cell transfection was performed for $24 \mathrm{~h}$ following the manufacturer's protocols prior to further experiments.

Statistical analysis. SPSS software (version 17.0; SPSS, Inc.) was used for statistical analysis. Data are expressed as the mean \pm standard deviation. Differences among multiple groups were analyzed by one-way ANOVA with Duncan's multiple range test; the unpaired Student' t-test was used for comparisons between two groups. $\mathrm{P}<0.05$ was considered to indicate a statistically significant difference. 


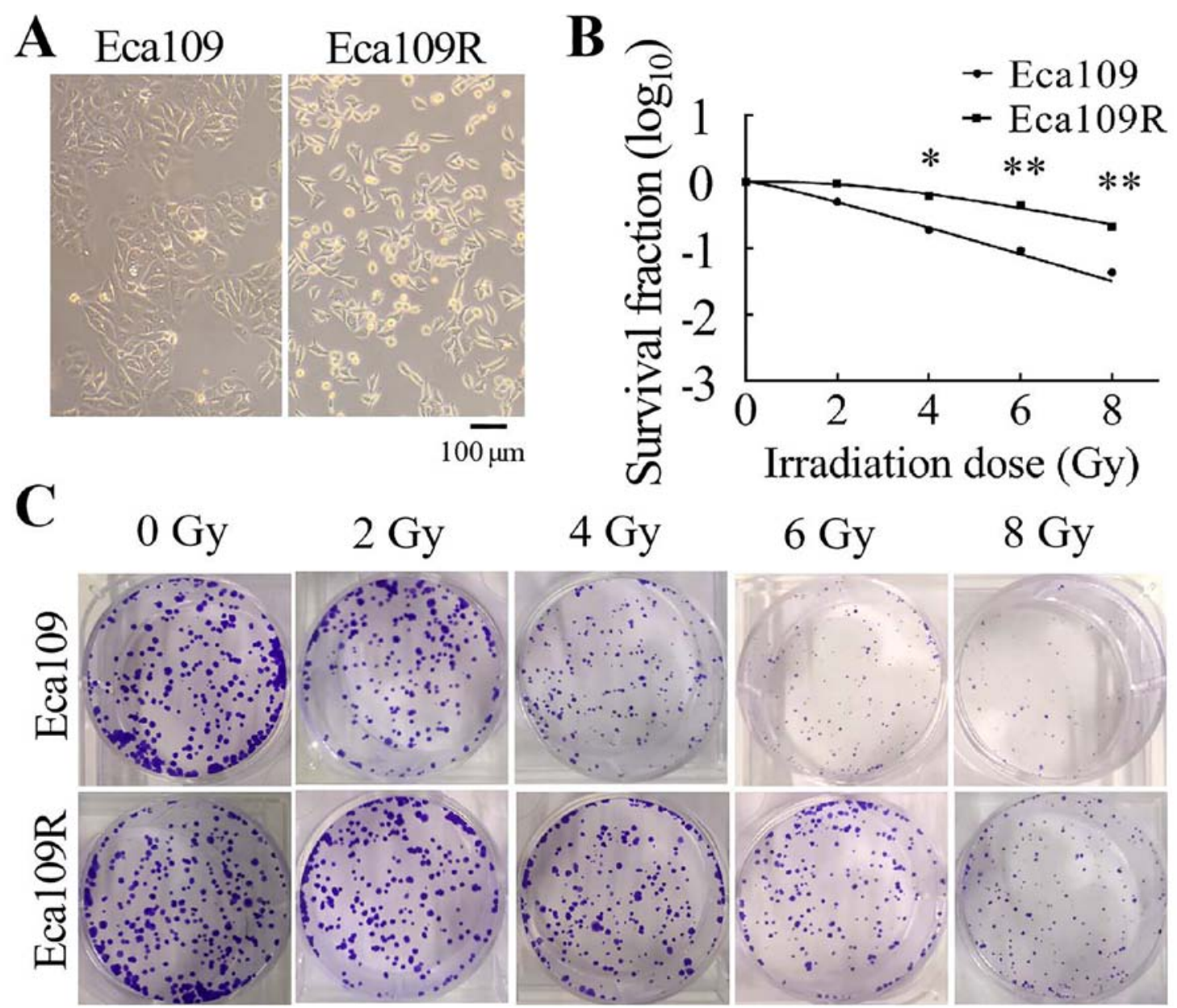

Figure 1. Radiosensitivity of Eca109 and Eca109R cells. (A) Morphological difference between Eca109 and Eca109R cells. (B) Survival fraction of Eca109 and Eca109R cells exposed to different doses of radiation. Data are presented as the mean \pm standard deviation. ${ }^{*} \mathrm{P}<0.05$ and ${ }^{* *} \mathrm{P}<0.01$ vs. Eca109. (C) Representative colony formation images of Eca109 and Eca109R cells exposed to different doses of radiation.

\section{Results}

Differences between the Ecal09 parental and Ecal09R radiation-resistant cell lines. The Eca109R radiation-resistant cell line was established by repeated irradiation of the Eca109 parental cell line with $2 \mathrm{~Gy} /$ time (cumulative $60 \mathrm{~Gy}, 30$ times in total). The morphology of the cells was observed using a light microscope (Olympus Corporation). At a higher magnification, Eca109 cells appeared as spherical or irregular polygons with a high degree of nuclear chromosome refractivity, whereas Eca109R cells appeared as irregular shuttle shapes with dense granular cytoplasm and small nuclei (Fig. 1A).

A colony formation assay was performed to characterize the radiosensitivity of Eca109 and Eca109R cells. The cells were seeded into six-well plates at different concentrations (400, $400,800,1,000$ and 1,200 cells/well) and received irradiation at different doses $(0,2,4,6$ and $8 \mathrm{~Gy})$. Following irradiation, the survival fraction of the two cell lines was measured. Cell survival curves were generated using the single-hit multi-target mode (Fig. 1B). The results demonstrated that with the radiation dose increasing, cell survival rate gradually decreased and Eca109 cells were more sensitive to radiation than Eca109R cells (Fig. 1C). Radiological measurements of Dq, D0 and N values were higher in Eca109R cells compared with those in Eca109 cells (Table I). Thus, the Eca109R cell line exhibited
Table I. Radiobiological parameters of Eca109 and Eca109R cells.

\begin{tabular}{lccc}
\hline Group & Eca109 & Eca109R & P-value \\
\hline $\mathrm{N}$ & $1.426 \pm 0.395$ & $3.310 \pm 0.200$ & 0.032 \\
$\mathrm{D} 0(\mathrm{~Gy})$ & $2.142 \pm 0.332$ & $3.092 \pm 0.153$ & 0.024 \\
$\mathrm{Dq}(\mathrm{Gy})$ & $0.944 \pm 0.157$ & $3.692 \pm 0.101$ & 0.041 \\
$\mathrm{SF}_{2}(\%)$ & $0.499 \pm 0.042$ & $0.937 \pm 0.013$ & 0.027 \\
\hline
\end{tabular}

$\mathrm{N}$, value of curve extension to the Y-axis intercept; D0, average lethal dose; $\mathrm{Dq}$, quasi-threshold dose; $\mathrm{SF}_{2}$, cell survival fraction following irradiation with $2 \mathrm{~Gy}$.

higher resistance to irradiation compared with the Eca109 cell line.

Different expression of key factors in Shh signaling pathway between the Ecal09 parental and Ecal09R radiation-resistant cell lines. Gli1 expression and localization were determined through immunofluorescence. The results demonstrated that although Gli1 was present in the nucleus and cytoplasm of Eca109 and Eca109R cells (Fig. 2), and that Gli1 appeared 


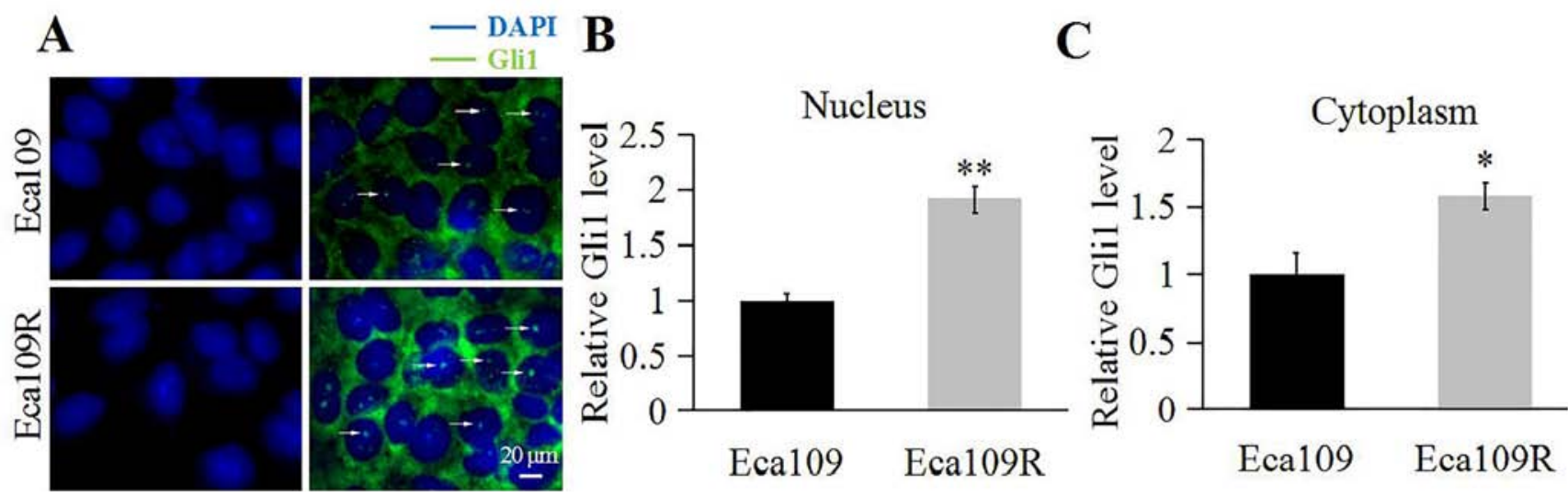

Figure 2. Gli1 expression in Eca109 and Eca109R cells. (A) Gli1 appeared abundant in the nucleus and the cytoplasm of Eca109R cells. Magnification, x40. Relative expression level of Gli1 in (B) the nuclei and (C) the cytoplasm of Eca109 and Eca109R cells. Data are presented as the mean \pm standard deviation. ${ }^{*} \mathrm{P}<0.05$ and ${ }^{* *} \mathrm{P}<0.01$ vs. Eca109. Gli1, glioma-associated oncogene family zinc finger 1.
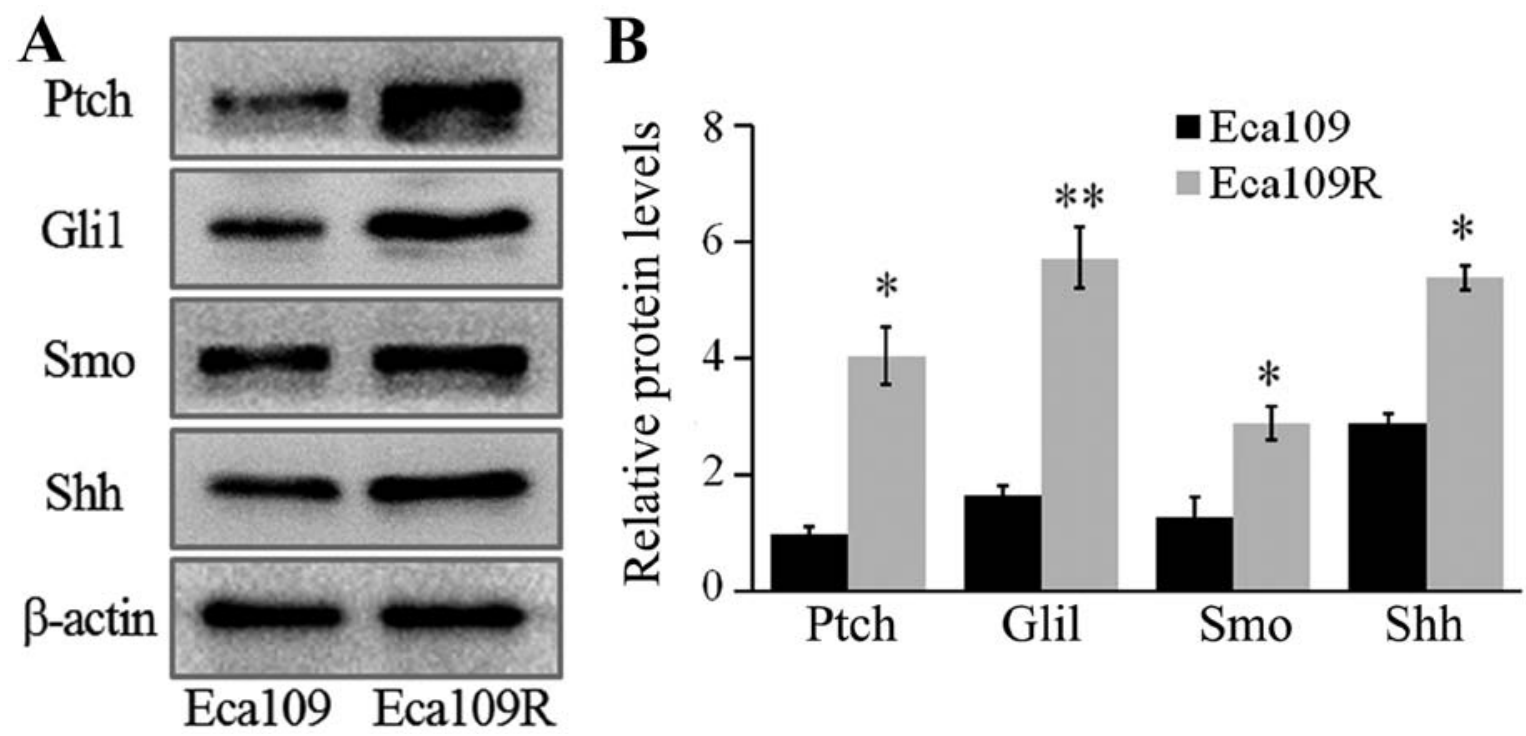

Figure 3. Protein expression levels of key factors in the Shh signaling pathway in Eca109 and Eca109R cells. Data are presented as the mean \pm standard deviation. "P $<0.05$ and ${ }^{* *} \mathrm{P}<0.01$ vs. Eca109. Ptch, patched 1; Gli1, glioma-associated oncogene family zinc finger 1; Smo, smoothened frizzled class receptor; Shh, Sonic Hedgehog.

abundant in the nucleus and the cytoplasm of Eca109R cells (Fig. 2A) compared with Eca109 cells (Fig. 2B and C).

The expression levels of Gli1, patched 1 (Ptch), smoothened frizzled class receptor (Smo) and Shh were detected by western blotting, and the results revealed that the expression levels of these proteins were significantly higher in Eca109R, compared with Eca109 cells $(\mathrm{P}<0.05$; Fig. 3). Thus, these results demonstrated a significant upregulation of the proteins in the Shh signaling pathway in radiation-resistant cells.

Decreased Ecal09 cell radiosensitivity following Gli1 overexpression. The results of plasmid construction were confirmed by sequencing and through enzyme digestion using both EcoRI and XhoI, generating fragments of 3 and $5 \mathrm{~kb}$ in length (Fig. 4). This confirmed the correct insertion of the target fragment and accurate construction of the pGli1-IRES-EGFP plasmid. Gli1 overexpression was established by transfecting the pGli1-IRES-EGFP plasmid into the Eca109 cell line, while the NC (empty plasmid) was transfected as a negative control, and the control group contained untransfected Eca109 cells. Following $48 \mathrm{~h}$ of transfection, the cells were identified using fluorescence microscopy. The transfection efficiency reached $\sim 70 \%$ (Fig. 5A). Next, the protein expression level of Gli1 was detected by western blotting analysis; the results indicated significantly higher levels of Gli1 expression in cells transfected with pGli1-IRES-EGFP compared with those in the two control groups (both $\mathrm{P}<0.05$; Fig. 5B and $\mathrm{C}$ ).

Transfection of Eca109 cells with the pGli1-IRES-EGFPplasmid established the association between overexpression of Gli1 and the radiosensitivity of the cells. The three cell types were seeded into 6-well plates and then irradiated at 0,2, 4, 6 and $8 \mathrm{~Gy}$, with a mean dose rate of $200 \mathrm{cGy} / \mathrm{min}$, followed by 2 weeks of culture. A clone formation assay was performed to measure the survival fraction of each experimental group, and the single-hit multi-target mode was used to establish cell survival curves (Fig. 5D). The results demonstrated that 
Table II. Comparison of radiobiological parameters of transfected Eca109 cells.

\begin{tabular}{lcccc}
\hline Group & Control & $\begin{array}{c}\text { Negative } \\
\text { control }\end{array}$ & $\begin{array}{c}\text { pGli1- } \\
\text { IRES-EGFP }\end{array}$ & P-value \\
\hline $\mathrm{N}$ & $0.736 \pm 0.157$ & $1.732 \pm 0.810$ & $1.909 \pm 0.662$ & 0.113 \\
$\mathrm{D} 0(\mathrm{~Gy})$ & $1.945 \pm 1.266$ & $2.084 \pm 0.525$ & $3.516 \pm 0.722$ & 0.049 \\
$\mathrm{Dq}(\mathrm{Gy})$ & $0.432 \pm 1.186$ & $0.826 \pm 0.752$ & $1.984 \pm 0.604$ & 0.007 \\
$\mathrm{SF}_{2}(\%)$ & $0.350 \pm 0.029$ & $0.532 \pm 0.062$ & $0.760 \pm 0.033$ & 0.001 \\
\hline
\end{tabular}

$\mathrm{N}$, value of curve extension to the Y-axis intercept; D0, average lethal dose; $\mathrm{Dq}$, quasi-threshold dose; $\mathrm{SF}_{2}$, cell survival fraction following irradiation with $2 \mathrm{~Gy}$.

Table III. Comparison of radiobiological parameters of transfected Eca109R cells.

\begin{tabular}{lcccc}
\hline Group & Control & $\begin{array}{c}\text { Negative } \\
\text { control }\end{array}$ & sh-Gli1 & P-value \\
\hline $\mathrm{N}$ & $3.456 \pm 0.297$ & $4.087 \pm 0.121$ & $2.134 \pm 0.221$ & 0.047 \\
$\mathrm{D} 0(\mathrm{~Gy})$ & $3.698 \pm 0.331$ & $1.916 \pm 0.193$ & $0.902 \pm 0.038$ & 0.039 \\
$\mathrm{Dq}(\mathrm{Gy})$ & $3.057 \pm 0.222$ & $2.978 \pm 0.227$ & $1.282 \pm 0.081$ & 0.021 \\
$\mathrm{SF}_{2}(\%)$ & $0.916 \pm 0.128$ & $0.867 \pm 0.070$ & $0.446 \pm 0.010$ & 0.034 \\
\hline
\end{tabular}

$\mathrm{N}$, value of curve extension to the Y-axis intercept; D0, average lethal dose; $\mathrm{Dq}$, quasi-threshold dose; $\mathrm{SF}_{2}$, cell survival fraction following irradiation with $2 \mathrm{~Gy}$.

with the radiation dose increasing, cell survival rate gradually decreased and pGli1-IRES-EGFP-transfected Eca109 cells were more resistant to radiation. The two control groups exhibited significantly lower D0 and Dq values compared with the pGli1-IRES-EGFP-transfected Eca109 cells $(\mathrm{P}<0.05$; Table II). The $\mathrm{SF}_{2}$ in pGli1-IRES-EGFP-transfected Eca109 cells was $0.760 \pm 0.033$, whereas those in the $\mathrm{NC}$ and control groups were $0.532 \pm 0.062$ and $0.350 \pm 0.029$, respectively (Table II). These findings demonstrated a reduction in radiation sensitivity in Eca109 cells following Glil overexpression (Table II). Therefore, the transfection of Eca109 cells with the pGli1-IRES-EGFP established an association between overexpression of Gli1 and the radiosensitivity of the cells.

Increased Ecal09R cell radiosensitivity may be attributed to Glil knockdown. Reduced Gli1 expression was established by transfecting the Gli1-silencing plasmid into the Eca109R cell line. The non-targeted Glil plasmid was transfected into the Eca109R cell line to create the NC, and the control group contained untransfected Eca109R cells. The transfection efficiency of the Gli1-silencing plasmid in Eca109R cells was analyzed using fluorescence microscopy after $48 \mathrm{~h}$. Green fluorescence confirmed successful transfection, and the transfection efficiency reached $\sim 70 \%$ (Fig. 6A). Gli1 expression levels were significantly lower in sh-Gli1-transfected Eca109R cells compared with the NC and control groups, as determined by western blotting $(\mathrm{P}<0.05$; Fig. $6 \mathrm{~B}$ and $\mathrm{C})$. These results

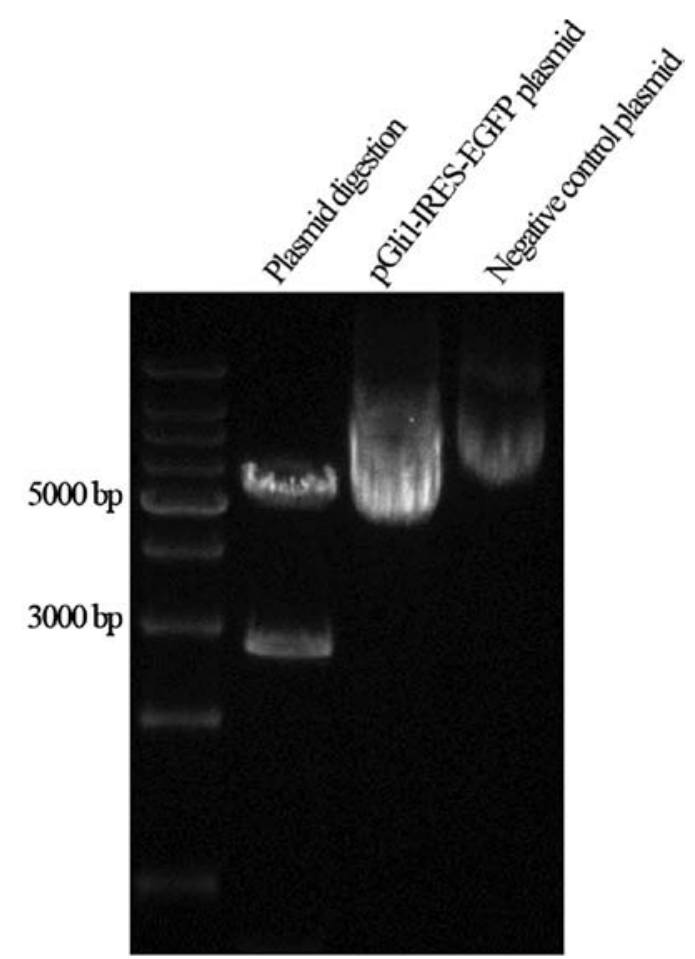

Figure 4. Electrophoretic map of plasmid restriction enzyme digestion. Gli1, glioma-associated oncogene family zinc finger 1.

indicated the effective generation of a Gli1-silenced Eca109R cell line.

The cells were harvested, seeded into six-well plates, irradiated and cultured over two weeks, followed by staining and counting. $\mathrm{SF}_{2}$ was measured, and the single-hit multi-target model was used to establish cell survival curves (Fig. 6D). The results indicated that with the radiation dose increasing, cell survival rate gradually decreased and Gli1-silenced Eca109R cells were more sensitive to radiation. The Gli1-silenced Eca109R cells exhibited significantly lower levels of the radiation-associated biological measurements (Dq, D0 and N values) compared with the two control groups $\left(\mathrm{P}<0.05\right.$; Table III). The $\mathrm{SF}_{2}$ in the sh-Gli1 plasmid-transfected Eca109R cell line was $0.446 \pm 0.010$, whereas in the $\mathrm{NC}$ and the control groups it was $0.867 \pm 0.070$ and $0.916 \pm 0.128$, respectively (Table III). These results indicated that the radiosensitivity of Eca109R Gli1-silenced cell line was significantly enhanced and that the radioresistance was weakened.

\section{Discussion}

EC frequently occurs as a primary tumor in the upper gastrointestinal tract, and its malignant nature is harmful to humans (22). A primary form of treatment for EC is radiation therapy $(15,23)$. However, reduced radiosensitivity develops with gradual increases in the irradiation dose and frequency, leading to the development of radiotherapy-resistant tumors (24). The recurrence and metastasis of tumors have been widely attributed to radiotherapy resistance $(25,26)$, and the options available to individuals suffering from inoperable forms of EC are further reduced by the development of radioresistance $(27,28)$. 

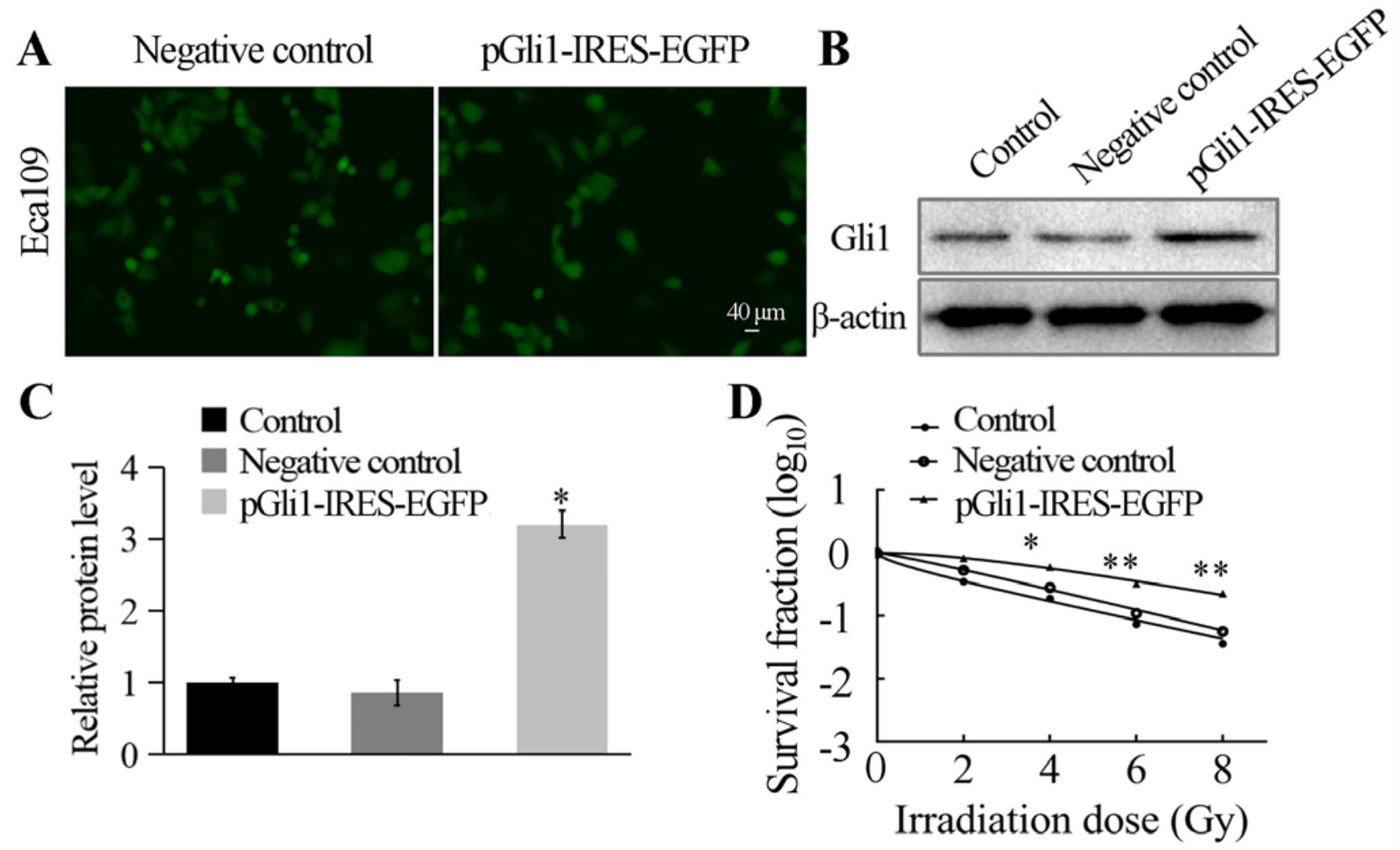

Figure 5. Gli1 overexpression decreases the sensitivity of Eca109 cells to radiation. (A) Eca109 cells were transfected with NC and pGli1-IRES-EGFP plasmids. Magnification, x10. (B and C) Expression levels of Gli1 protein in Eca109 cells after transfection. (D) Survival curves of control, NC and pGli1-IRES-EGFP-transfected Eca109 cells. Data are presented as mean \pm standard deviation. ${ }^{*} \mathrm{P}<0.05$ and ${ }^{* *} \mathrm{P}<0.01$ vs. negative control.Gli1, glioma-associated oncogene family zinc finger 1 ; NC, negative control.
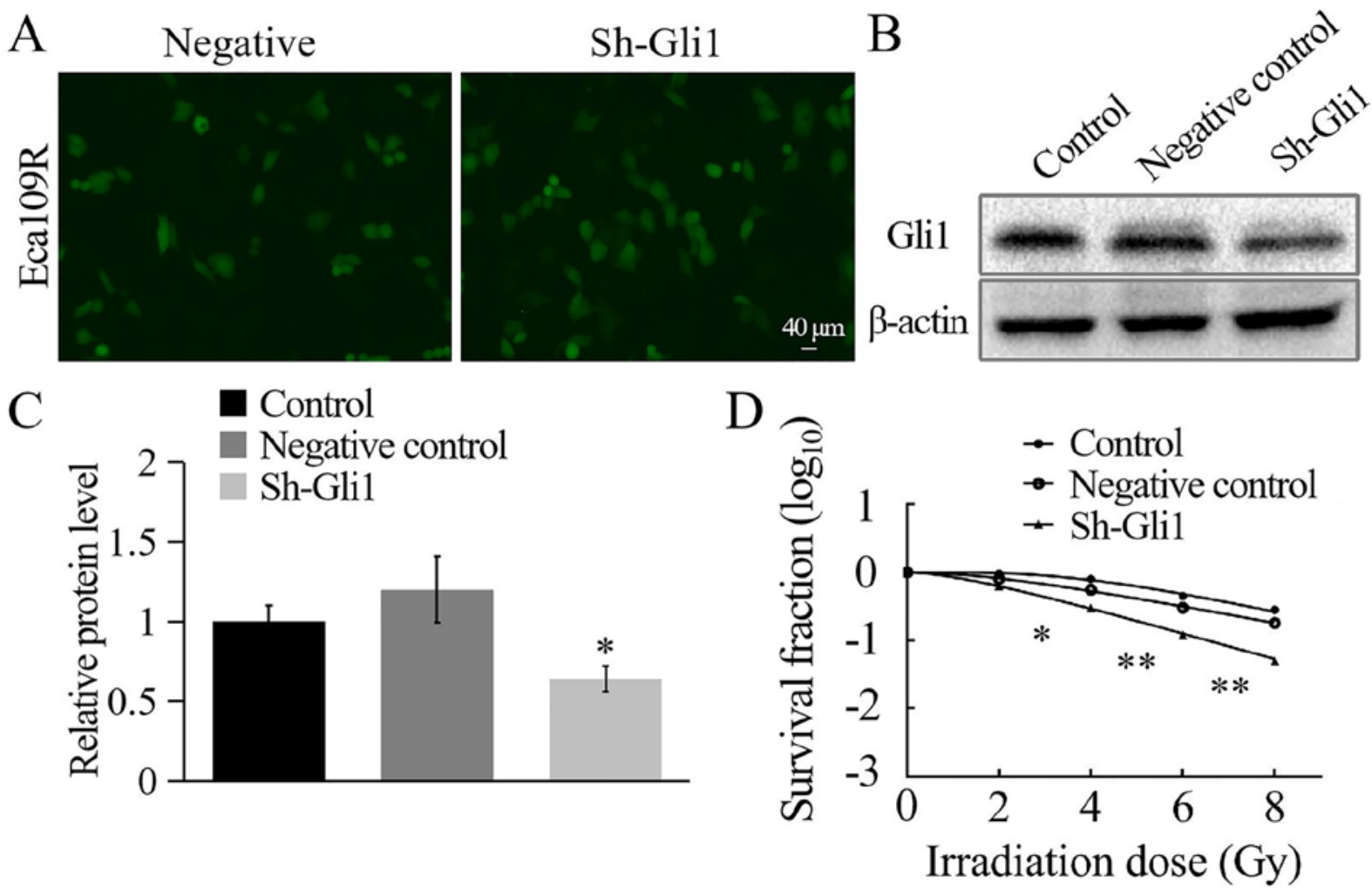

Figure 6. Silencing of Gli1 increased the sensitivity of Eca109R cells to radiation (x10 magnification). (A) Eca109R cells were transfected with NC and Gli1-silencing plasmids. (B and C) Expression levels of Gli1 protein in Eca109R cells following transfection. (D) Survival curves of control, NC and sh-Gli1 Eca109R cells. Data are presented as the mean \pm standard deviation. ${ }^{*} \mathrm{P}<0.05$ and ${ }^{* *} \mathrm{P}<0.01$ vs. negative control.Gli1, glioma-associated oncogene family zinc finger 1; sh, short hairpin (RNA); NC, negative control. 
To enhance the efficacy radiotherapy, it is crucial to research radioresistance mechanisms. Various studies have been performed on the mechanisms of radioresistance, including DNA damage and repair (29), cell proliferation and apoptosis (30), abnormal expression of microRNA and IncRNA (31-34) and disruption of the cell cycle (30) and altered expression of Shh signaling pathway (35). Xie et al (35) demonstrated that Raf kinase inhibitory protein reduction enhances radioresistance by activating the Shh signaling pathway. The present study also tried to explore whether radioresistance was associated with Shh signaling pathway activation.

The Sonic Hedgehog signaling pathway consists of Shh ligands, the transmembrane proteins Ptch and Smo, and the downstream Gli transcription factors (Gli1, Gli2 and Gli3) (36). Abnormal activation of the Shh signaling pathway is reliably detected through the expression of Gli1 $(37,38)$. An earlier study established the activation of the Shh signaling pathway during tissue repair and an absence of this signaling in normally-functioning adult tissues and organs (39). Furthermore, a previous study suggested an association between Shh signaling pathway activation and the development of resistance in a range of human cancer types, including EC (40).

In normal tissues, Smo protein activity is inhibited by Ptch (41). However, when Shh associates with Ptch, the Gli1 protein enters the nucleus to activate the transcription of the downstream target genes (42). Increased Gli1 expression levels were demonstrated in EC tissues and adjacent tissues compared with normal tissues (43), and Gli1 has been detected in the nuclei of a number of tumor-cell types. A recent study by Huang et al (44) demonstrated that Hh signaling pathway is activated in Hela-RR and Siha-RR, which was also demonstrated in the present study. Furthermore, the expression of Shh, Ptch and Smo has been detected in 34 ESCC cell lines, and Gli1 was highly expressed in 31 EC cell lines (45). In addition, silencing of Gli1 expression was achieved through specific inhibitors of Smo, which led to the inhibition of fission, recurrence and metastasis in ESCC (45). Glil transcription efficacy is positively associated with its expression, which can be used to efficiently detect abnormal activation of the Shh signaling pathway (46). The results of the current study revealed higher Gli1 protein expression levels in Eca109R cells, compared with Eca109 cells. Furthermore, Gli1 in radiation-resistant cells was aggregated around the nucleus, as determined by immunofluorescence. These results suggested an association between radioresistance in EC and the Shh signaling pathway.

The radiation-resistant cell line Eca109R was generated through low-level X-ray irradiation of the human EC cell line Eca109. Colony formation assays demonstrated higher measurements of the radiation-related biological parameters (D0, Dq and N) in Eca109R, compared with Eca109 cells, which indicated increased levels of resistance in the Eca109R cell line compared with the parental cells. Furthermore, the expression of Gli1, Ptch, Shh and Smo was confirmed by western blotting in Eca109 and Eca109R cells; all of the tested proteins exhibited significantly higher expression levels in Eca109R cells compared with Eca109 cells, and immunofluorescence displayed Gli1 protein aggregation around the nucleus. A previous study reported that Shh signaling pathway activation is associated with the development of esophageal squamous cell carcinoma (ESCC) (47). High expression of Shh signaling pathway-related genes is present in ESCC, and patients with high Gli1 expression in ESCC are not sensitive to radiation therapy (47), which was the case in the present study. A Gli1 overexpression plasmid was constructed and subsequently transfected into Eca109 cells, and analyses confirmed that Gli1 protein expression was increased. In addition, the clone formation assay showed that radiosensitivity was decreased in Gli1-overexpressing Eca109 cells compared with untransfected cells. Furthermore, the Eca109R cell line was transfected with a Gli-1 silencing plasmid. These cells exhibited significantly lower Gli1 expression levels and higher levels of radiosensitivity compared with the control groups. A previous study reported that Hh signaling pathway can influence the radiation response in some patient-derived murine xenograft (PDX) model of esophageal adenocarcinoma, and that inhibition of this pathway could increase the radiation efficacy (48). In conclusion, these findings demonstrated an association between Glil and radioresistance in EC.

The mechanism underlying radioresistance, which contributes to the pathogenicity of EC, is a complex process; further research into how the Shh signaling pathway impacts radioresistance is required. The present study described novel research that may be used as a foundation for future studies into the processes regulating Shh signaling pathway activation-induced radioresistance.

\section{Acknowledgements}

Not applicable.

\section{Funding}

The present study was supported by the Natural Science Foundation of Hubei Province of China (grant no. 2014CFB818).

\section{Availability of data and materials}

The datasets used and/or analyzed during the present study are available from the corresponding author on reasonable request.

\section{Authors' contributions}

QW, HLi, QL and HLo designed the experiments. FY, JY, YH and JL performed the experiments and analyzed all data. FY and JY drafted the manuscript and all authors approved the final version of the manuscript.

\section{Ethics approval and consent to participate}

Not applicable.

\section{Patient consent for publication}

Not applicable.

\section{Competing interests}

The authors declare that they have no competing interests. 


\section{References}

1. Bray F, Ferlay J, Soerjomataram I, Siegel RL, Torre LA and Jemal A: Global cancer statistics 2018: GLOBOCAN estimates of incidence and mortality worldwide for 36 cancers in 185 countries. CA Cancer J Clin 68: 394-424, 2018.

2. Lagergren J, Smyth E, Cunningham D and Lagergren P: Oesophageal cancer. Lancet 390: 2383-2396, 2017.

3. Sohda M and Kuwano H: Current status and future prospects for esophageal cancer treatment. Ann Thorac Cardiovasc Surg 23: 1-11, 2017.

4. Abnet CC, Arnold M and Wei WQ: Epidemiology of esophageal squamous cell carcinoma. Gastroenterology 154: 360-373, 2018

5. Lin Y, Totsuka Y, He Y, Kikuchi S, Qiao Y, Ueda J, Wei W, Inoue $\mathrm{M}$ and Tanaka $\mathrm{H}$ : Epidemiology of esophageal cancer in Japan and China. J Epidemiol 23: 233-242, 2013.

6. Keditsu KK, Jiwnani S, Karimundackal G and Pramesh CS Multimodality management of esophageal cancer. Indian J Surg Oncol 4: 96-104, 2013.

7. Januszewicz W and Fitzgerald RC: Early detection and therapeutics. Mol Oncol 13: 599-613, 2019.

8. Bird-Lieberman EL and Fitzgerald RC: Early diagnosis of oesophageal cancer. Br J Cancer 101: 1-6, 2009.

9. Guo X, Duan Y, Ye X, Hu L, Xu T, Tong L and Yu M: Stable silencing of dll4 gene suppresses the growth and metastasis of esophagus cancer cells by attenuating Akt phosphorylation. Oncol Rep 40: 495-503, 2018.

10. Alexandre L, Long E and Beales IL: Pathophysiological mechanisms linking obesity and esophageal adenocarcinoma. World J Gastrointest Pathophysiol 5: 534-549, 2014.

11. Qian X, Tan C, Wang F, Yang B, Ge Y, Guan Z and Cai J: Esophageal cancer stem cells and implications for future therapeutics. Onco Targets Ther 9: 2247-2254, 2016

12. Lou F, Sima CS, Adusumilli PS, Bains MS, Sarkaria IS Rusch VW and Rizk NP: Esophageal cancer recurrence patterns and implications for surveillance. J Thoracic Oncol 8: 1558-1562, 2013.

13. Domper Arnal MJ, Ferrandez Arenas A and Lanas Arbeloa A: Esophageal cancer: Risk factors, screening and endoscopic treatment in Western and Eastern countries. World J Gastroenterol 21: 7933-7943, 2015

14. Wu SG, Xie WH, Zhang ZQ, Sun JY, Li FY, Lin HX, Yong Bao and He ZY: Surgery combined with radiotherapy improved survival in metastatic esophageal cancer in a surveillance epidemiology and end results population-based study. Sci Rep 6: 28280, 2016

15. Ordu AD, Nieder C, Geinitz H, Kup PG, Deymann LF, Scherer V, Combs SE and Fakhrian K: Radio(chemo)therapy for locally advanced squamous cell carcinoma of the esophagus: Long-term outcome. Strahlenther Onkol 191: 153-160, 2015.

16. Malhotra A, Sharma U, Puhan S, Chandra Bandari N, Kharb A, Arifa PP, Thakur L, Prakash H, Vasquez KM and Jain A: Stabilization of miRNAs in esophageal cancer contributes to radioresistance and limits efficacy of therapy. Biochimie 156: 148-157, 2019

17. Hu YT, Li BF, Zhang PJ, Wu D, Li YY, Li ZW, Shen L, Dong B, Gao J and Zhu X: Dbx2 exhibits a tumor-promoting function in hepatocellular carcinoma cell lines via regulating Shh-Gli1 signaling. World J Gastroenterol 25: 923-940, 2019.

18. Liu X, Zhao T, Bai X, Li M, Ren J, Wang M, Xu R, Zhang S, Li H, Hu Y, et al: LOC101930370/MiR-1471 axis modulates the hedgehog signaling pathway in breast cancer. Cell Physio Biochem 48: 1139-1150, 2018.

19. Islam SS, Mokhtari RB, Noman AS, Uddin M, Rahman MZ, Azadi MA, Zlotta A, van der Kwast T, Yeger $\mathrm{H}$ and Farhat WA: Sonic hedgehog (Shh) signaling promotes tumorigenicity and stemness via activation of epithelial-to-mesenchymal transition (EMT) in bladder cancer. Mol Carcinog 55: 537-551, 2016.

20. Wang Z, Jiang J, Qin T, Xiao Y and Han L: EIF5A regulates proliferation and chemoresistance in pancreatic cancer through the SHH signalling pathway. J Cell Mol Med 23: 2678-2688, 2019.

21. Chen J, Wu QM, Long H, Zhang H and Chen JH: P162 enhances the radiosensitivity of esophageal cancer Eca109 cells by inhibiting Gli-1, the transcription factor of Hedgehog signaling pathway. World Chin J Digestology 22: 615-623, 2014

22. Lin Y, Totsuka Y, Shan B, Wang C, Wei W, Qiao Y, Kikuchi S, Inoue $\mathrm{M}$, Tanaka $\mathrm{H}$ and $\mathrm{He} \mathrm{Y}$ : Esophageal cancer in high-risk areas of China: Research progress and challenges. Ann Epidemiol 27: 215-221, 2017.
23. Xi M and Lin SH: Recent advances in intensity modulated radiotherapy and proton therapy for esophageal cancer. Expert Rev Anticancer Ther 17: 635-646, 2017.

24. Zhang YY, Wang LB, Zhao Q, Li G, Gong SL and Dong LH: Advanced research on relationship between tumor microenvironment and radiosensitivity of tumor cells. J Jilin University (Medical Edition) 42: 1038-1044, 2016.

25. Shen C, Chen F, Wang H, Li G, Yu C, Wang X and Wen Z: The Pinx1 gene downregulates telomerase and inhibits proliferation of CD133+ cancer stem cells isolated from a nasopharyngeal carcinoma cell line by regulating Trfs and Mad1/C-Myc/p53 pathways. Cell Physiol Biochem 49: 282-294, 2018.

26. SharmaBK, Manglik V,O'Connell M, Weeraratna A,McCarronEC, Broussard JN, Divito KA, Simbulan-Rosenthal CM, Rosenthal DS and Zapas JL: Clonal dominance of CD133+ subset population as risk factor in tumor progression and disease recurrence of human cutaneous melanoma. Int J Oncol 41: 1570-1576, 2012.

27. Siersema PD and Van Hillegersberg R: Treatment of locally advanced esophageal cancer with surgery and chemoradiation. Curr Opin Gastroenterol 24: 535-540, 2008.

28. Koike R, Nishimura Y, Nakamatsu K, Kanamori S and Shibata T: Concurrent chemoradiotherapy for esophageal cancer with malignant fistula. Int J Radiat Oncol Biol Phys 70: 1418-1422, 2008.

29. Zhou Y, Chu L, Wang Q, Dai W, Zhang X, Chen J, Li L, Ding P, Zhang L, Gu H, et al: CD59 is a potential biomarker of esophageal squamous cell carcinoma radioresistance by affecting DNA repair. Cell Death Dis 9: 887, 2018.

30. Pan S, Sun Y, Sui D, Yang T, Fu S, Wang J, Hui B, Xi R, He C and Zhang $\mathrm{X}$ : Lobaplatin promotes radiosensitivity, induces apoptosis, attenuates cancer stemness and inhibits proliferation through PI3K/AKT pathway in esophageal squamous cell carcinoma. Biomed Pharmacother 102: 567-574, 2018.

31. Park M, Yoon HJ, Kang MC, Kwon J and Lee HW: MiR-338-5p enhances the radiosensitivity of esophageal squamous cell carcinoma by inducing apoptosis through targeting survivin. Sci Rep 7: 10932, 2017.

32. Zang $\mathrm{C}$, Zhao F, Hua $\mathrm{L}$ and $\mathrm{Pu} \mathrm{Y}$ : The miR-199a-3p regulates the radioresistance of esophageal cancer cells via targeting the AK4 gene. Cancer Cell Int 18: 186, 2018.

33. Zhang H, Hua Y, Jiang Z, Yue J, Shi M, Zhen X, Zhang X, Yang L, Zhou R and Wu S: Cancer-associated fibroblast-promoted LncRNA DNM3OS confers radioresistance by regulating DNA damage response in esophageal squamous cell carcinoma. Clin Cancer Res 25: 1989-2000, 2019.

34. Li Z, Zhou Y, Tu B, Bu Y, Liu A and Kong J: Long noncoding RNA MALAT1 affects the efficacy of radiotherapy for esophageal squamous cell carcinoma by regulating Cks1 expression. J Oral Pathol Med 46: 583-590, 2017.

35. Xie SY, Li G, Han C, Yu YY and Li N: RKIP reduction enhances radioresistance by activating the Shh signaling pathway in non-small-cell lung cancer. Onco Targets Ther 10: 5605-5619, 2017.

36. Wu G, Chen G, Zhou J, Zhu H, Chu J and Zhang F: Liriodenine enhances radiosensitivity in esophageal cancer ECA109 cells by inducing apoptosis and G2/M arrest. Oncol Lett 16: 5020-5026, 2018.

37. Hu L, Lin X, Lu H, Chen B and Bai Y: An overview of hedgehog signaling in fibrosis. Mol Pharmacol 87: 174-182, 2015.

38. Zhu SL, Luo MQ, Peng WX, Li QX, Feng ZY, Li ZX, Wang MX, Feng XX, Liu F and Huang JL: Sonic hedgehog signalling pathway regulates apoptosis through Smo protein in human umbilical vein endothelial cells. Rheumatology (Oxford) 54: 1093-1102, 2015

39. Tanaka T, Arai M, Minemura S, Oyamada A, Saito K, Jiang X, Tsuboi M, Sazuka S, Maruoka D, Matsumura T, et al: Expression level of sonic hedgehog correlated with the speed of gastric mucosa regeneration in artificial gastric ulcers. J Gastroenterol Hepatol 29: 736-741, 2014.

40. Wadhwa R, Wang X, Baladandayuthapani V, Liu B, Shiozaki H, Shimodaira Y, Lin Q, Elimova E, Hofstetter WL, Swisher SG, et al: Nuclear expression of Gli-1 is predictive of pathologic complete response to chemoradiation in trimodality treated oesophageal cancer patients. Br J Cancer 117: 648-655, 2017.

41. Briscoe J and Thérond PP: The mechanisms of hedgehog signalling and its roles in development and disease. Nat Rev Mol Cell Biol 14: 416-429, 2013.

42. Miele E, Po A, Begalli F, Antonucci L, Mastronuzzi A, Marras CE, Carai A, Cucchi D, Abballe L, Besharat ZM, et al: $\beta$-arrestinl-mediated acetylation of Gli1 regulates Hedgehog/ Gli signaling and modulates self-renewal of SHH medulloblastoma cancer stem cells. BMC Cancer 17: 488, 2017. 
43. Wei L and $\mathrm{Xu} \mathrm{Z}$ : Cross-signaling among phosphinositide-3 kinase, mitogen-activated protein kinase and sonic hedgehog pathways exists in esophageal cancer. Int J Cancer 129: 275-284, 2011.

44. Huang C, Lu H, Li J, Xie X, Fan L, Wang D, Tan W, Wang Y, Lin $Z$ and Yao T: SOX2 regulates radioresistance in cervical cancer via the hedgehog signaling pathway. Gynecol Oncol 151: 533-541, 2018.

45. Mori Y, Okumura T, Tsunoda S, Sakai Y and Shimada Y: Gli-1 expression is associated with lymph node metastasis and tumor progression in esophageal squamous cell carcinoma. Oncology 70: 378-389, 2006

46. Cheng J, Gao J and Tao K: Prognostic role of Glil expression in solid malignancies: A meta-analysis. Sci Rep 6: 22184, 2016.
47. Zhu W, You Z, Li T, Yu C, Tao G, Hu M and Chen X: Correlation of hedgehog signal activation with chemoradiotherapy sensitivity and survival in esophageal squamous cell carcinomas. Jpn J Clin Oncol 41: 386-393, 2011.

48. Teichman J, Dodbiba L, Thai H, Fleet A, Morey T, Liu L, McGregor M, Cheng D, Chen Z, Darling G, et al: Hedgehog inhibition mediates radiation sensitivity in mouse xenograft models of human esophageal adenocarcinoma. PLoS One 13: e0194809, 2018.

(i) (9) This work is licensed under a Creative Commons Attribution-NonCommercial-NoDerivatives 4.0 International (CC BY-NC-ND 4.0) License. 